\title{
Öğretmen Adaylarının Özgüvenleri ile Teknoloji Kullanımları Arasındaki İlişkinin İncelenmesi*
}

\author{
Mahmut ÇALIŞKAN \\ Yüksek Lisans Öğrencisi, Necmettin Erbakan Üniversitesi, Eğitim Bilimleri Enstitüsü, Konya, Türkiye, \\ mahmut.caliskan9442@gmail.com
}

Ahmet Naci ÇOKLAR

Doç. Dr. Necmettin Erbakan Üniversitesi, Ahmet Keleşoğlu Eğitim Fakültesi, Bilgisayar ve Öğretim

Teknolojileri

Eğitimi Bölümü, Konya, Türkiye,

ahmetcoklar@hotmail.com

\section{ARAŞTIRMA MAKALESİ/RESEARCH ARTICLE}

\begin{tabular}{|c|c|}
\hline Makale Bilgileri & ÖZ \\
\hline Makale Ge & Bu çalışmada öğretmen adayların özgüvenleri ile teknoloji kullanımları arasındaki \\
\hline Gelis: 17.06.2019 & ilişki incelenmiştir. Tarama modeli kullanılarak yapılan araştırmada 345 kişilik \\
\hline & gurubundan very toplanmıştır. Araştırmada veri toplama aracı olarak \\
\hline & en düzeylerini belirlemek için “Özgüven Ölçeği” ile öğretmen adaylarının \\
\hline Yayın: 20.12.2019 & $\begin{array}{l}\text { teknoloji tutumların belirlemek için "Öğretmen Adayları için Bilgi ve İletişim } \\
\text { Teknolojileri (BİT) Yeterlilik Algısı Ölçeği" kullanılmıştır. Araştırma sonucunda, } \\
\text { öğretmen adaylarının özgüven ve BİT yeterlilik alglarının cinsiyet değişkenine } \\
\text { göre incelendiğinde istatistiki açıdan anlamlı farklılık olmadığ görülmüştür. } \\
\text { Öğretmen adaylarının özgüven aylık ortalama gelir değişkeni açısından } \\
\text { incelendiğinde ise özgüvenleri acısından gelir düzevi vüksek olanlar lehine }\end{array}$ \\
\hline Anahtar Kelimeler: & farklılaștığı fakat BIT yeterlilik açısından anlamlı farklılığın bulunmadığ \\
\hline Özgüven, & gözlenmiştir. Araștırma bulgularına göre öğretmen adaylarının özgüven düzeyleri \\
\hline BİT Yeterlik Algısı, & $\begin{array}{l}\text { ve BIT yeterlilik algıları arasında orta ve pozitif yönlü bir ilişki tespit edilmiștir. } \\
\text { Özgüveni yüksek öğretmen adaylarının BİT kullanım yeterlilik algılarının yüksek }\end{array}$ \\
\hline Öğretmen Adayları. & $\begin{array}{l}\text { olduğu ve daha emin ve kendilerine güvenen, teknolojik sistemleri daha kolay } \\
\text { kullandıkları. BìT kullanımını daha kolay öğrendikleri sonucuna varılmıstır. }\end{array}$ \\
\hline
\end{tabular}

* Bu çalışma, Uluslararası V. Turkcess Eğitim ve Sosyal Bilimler Kongresinde bildiri olarak sunulmuştur. 


\section{Investigating the Relationship Between Pre-Service Teachers' Self-Confidence and Technology Usage}

\begin{tabular}{|c|c|}
\hline Article Info & ABSTRACT \\
\hline Article History & In this study, the relationship between the self-confidence of teacher candidates \\
\hline Received: 27.06 .2019 & and their use of technology was investigated. A 345-person study group was used \\
\hline heter & in the survey. In this study, a "self-confidence scale" and a "knowledge and \\
\hline Accepted: 27.08 .2019 & communication technologies (ICT) competency scale for teacher candidates" were \\
\hline Published: 20.12 .2019 & $\begin{array}{l}\text { used to determine the technological attitudes of teacher candidates. As a result of } \\
\text { the research, it was observed that the perceptions of self-confidence and ICT } \\
\text { competence of teacher candidates were examined according to gender variables } \\
\text { and there was no statistically significant difference. It was observed that teachers' }\end{array}$ \\
\hline Keywords: & $\begin{array}{l}\text { perceptions of self-confidence were different in terms of monthly average income, } \\
\text { but there was no significant difference in ICT compentences. According to the }\end{array}$ \\
\hline Self-confidence, & research findings, a middle and positive correlation was found between self- \\
\hline $\begin{array}{l}\text { ICT competence } \\
\text { perception, }\end{array}$ & $\begin{array}{l}\text { confidence levels and lice competency perceptions of teacher candidates. It has } \\
\text { been concluded that higher self-confidence teachers have higher perception of ICT }\end{array}$ \\
\hline Teacher candidates. & $\begin{array}{l}\text { proficiency and that they are more confident and confident, they use technological } \\
\text { systems more easily, they learn ICT easier to use. }\end{array}$ \\
\hline
\end{tabular}

\section{GİRIŞ}

Teknoloji ve eğitim insan yaşamını etkileyen ve hızlı değişim gösteren önemli iki kavramdır (Simon, 1983; McCannon ve Crews, 2000; Komis vd., 2007). Eğitim teknolojiye göre daha geniş bir kavram olup tüm olguları kapsamaktadır. Eğitimi, "bireyin davranışında kendi yaşantısı yoluyla ve kasıtlı olarak istendik değişme meydana getirme süreci" olarak tanımlayan Ertürk (1997), eğitimin çok geniş bir kavram olduğunu dile getirmiştir. Bir diğer kavram olan teknoloji ise insan yaşamını kolaylaştıran sistemler örüntüsü olup, insan yaşamını kolaylaştırmanın yanında bilimsel açıdan da büyük bir öneme sahiptir (Erdemir, 2009; Bakırcl, 2009; Eyduran, 2009). Teknolojinin kullanıldığı en önemli alanlardan birisi de eğitimdir. Bu açıdan eğitimde teknoloji kullanımı insanlar ve ülkeler için büyük öneme sahiptir (Aksoy, 2003). Hızla gelișen ve değișen dünyada bu iki kavramı birbirinden ayrı düşünmek pekte mümkün değildir.

Bir hedefe ulaşabilmenin yolu o hedef ile ilişkili unsurların niteliğine ve birbirleri ile olan ilişkilerine bağlıdır. Bu sebepten dolayı eğitimin hedeflerine ulaşabilmenin yolu bireyleri okulda veya okul dışında etkileyen etmenleri iyi tespit edebilmek, niteliklerini artırmak ve unsurlar arasında olumlu ilişkiler kurabilmekten geçer. Bu unsurlardan en aktif unsurlardan birisi de öğretmen unsurudur ve öğretmenlerin mesleğe yönelik tutumları ile eğitim hedeflerinin arasında bağlantılı bir ilişki söz konusudur (Sayan, 2016). Öğretmenin mesleğe yönelik tutumları öğrencilerin eğitim hedeflerine ulaşmasında önemli bir unsurdur (Sayan, 2015). Öğretmenlerin mesleki tutum ve bilgilerini geliştirme ve iyileştirme çalışmalarında teknoloji tutumları da büyük önem taşımaktadır (Usta, 2010).

Teknoloji, bilimsel ilke ve yeniliklerin problemlerin çözümlerine yönelik uygulanmasıdır. En geniş anlamıyla teknoloji bir bilim uygulamasıdır (Aksoy, 2003). Bütün teknolojik cihazlar bilimsel problemlerin çözümü için uygulanması sonucu ortaya çıkan araçlar olarak görülmektedir. Bu bağlamda teknoloji insan yaşamında kültürel ve sosyal birçok alanı etkileyen önemli etmenlerden birdir. Yapılan alanyazın çalışmaları doğrultusunda elde edilen bilgiler ışığında teknolojinin eğitim alanında da yaygın olarak kullanıldığı gözlemlenmiştir. Teknolojinin eğitim alanında kullanımı radyo, tv, video ve tepegöz gibi araçların okullarda kullanımına bağlı olarak çok eski tarihlere gidilebilmekle birlikte günümüz eğitim sisteminin gelişiminin ve niteliğinin artmasında en önemli etken eğitim alanında bilgisayar, internet ve bunlar ile ilişkili araçların kullanımının yaygınlaşması ile mümkün olmuştur (Aksoy,2003). 
Araştırma kapsamında ele alınan bir diğer konu ise özgüvendir. Özgüven, literatürdeki haliyle "bireyin kendisini değerli hissetmesi yargısıdır" (Bandura, 1997: 11). Özgüven genel anlamda karakter özelliğidir, geçici veya kalıcı davranış çeșidi değildir (Özevin Tokinan, 2008). Kişinin özgüven durumu bütün yaşamını olumu veya olumsuz şekilde etkilemektedir ve yüksek özgüvene sahip bireyler akademik sosyal ve kişilik karakter gibi durumlarda olumlu sonuçlar elde edildiği ifade edilmektedir (Shrauger, 1972; Franken, 1988: ss 404). Özgüven algısı yüksek bireylerin zihinsel ya da fizyolojik tutumlarında daha pozitif sonuçlar alındığı bilinmektedir (Altunçekiş, Yaman ve Koray, 2005). Özgüven kişilik üzerinde de etkili olmuştur. Özgüveni yüksek kişiler araştırma yapmayı seven yenilikçi, sorumluluklarının bilincinde olan aktif bir kişilik özelliklerine sahiptirler ve özgüveni yüksek kişiler elindeki imkânların farkında çevresine ve kendine karşı bilinçli, oturmuş karakteristik özelliklere sahip bireylerdir (Soner, 1995).

Öğretmen adaylarının özgüvenlerinin yüksek olması, eğitimin hedeflerine ulaşma gayesinde olumlu sonuçlar elde edilmesini sağlayacaktır.

\section{Araştırmanın Önemi}

Teknoloji ve özgüven kavramları sosyal kültürel açıdan birçok alanı etkileyen insan üzerinde derin izler bırakan önemi günümüz dünyasında giderek artan iki kavram olarak karşımıza çıkmaktadır. Bu araştırmanın amacı bu iki kavramın birbirleri ile olan ilişkilerini belirlemektir. $\mathrm{Bu}$ kapsamda elde edilen veriler ışığında psikolojik bir etmen olarak öğretmen adaylarının özgüven düzeylerinin teknoloji kullanımları ile ilişkilerini belirlemek önemli görülmüș ve araștırılmıștır. Böylelikle teknoloji tutumları ve davranıșları gelișen, özgüven sebebiyle teknoloji tutumlarını yerine getiremeyen eğitimcilerin sorunlarını çözmek, eğitimde teknolojiden daha sağlıklı yararlanmalarına yönelik çıkarımlar geliştirmek hedeflenmiştir.

\section{Araştırmanın Amacı}

$\mathrm{Bu}$ araştırmanın amacı öğretmen adaylarının özgüven düzeyleri ile teknoloji kullanım durumlarını belirlemek ve iki değiş̧ken arasındaki ilişkiyi ortaya koymaktır. Bu amaçla aşağıdaki sorulara yanıtlar aranmıştır.

1. Öğretmen adaylarının teknoloji kullanım durumları ve özgüven düzeyleri nedir?

2. Öğretmen adaylarının teknoloji kullanım durumları ve özgüven düzeyleri

a. Cinsiyet

b. Aylık ortalama gelir düzeyi

değişkenlerine göre farklılaşmakta mıdır?

3. Öğretmen adaylarının teknoloji kullanım durumları ile özgüven düzeyleri arasında nasıl bir ilişki vardır?

\section{YÖNTEM}

Bu bölümde araştırmanın yöntemine değinilmiştir. Araştırmada kullanılan model, evren ve örneklem, veri toplanmasıyla ilgili yapılan çalışmalar ve araştırmada kullanılan istatistiksel teknikler açıklanmıştır.

\section{Araştırmanın Modeli}

Öğretmen adaylarının özgüvenleri ve teknoloji kullanımları arasındaki ilișkinin incelendiği bu çalışmada ilişkisel tarama modeli kullanılmıştır. İlişiksel tarama modelleri iki veya daha fazla değişken arasındaki birlikte değișim olup olmadığını ve varlık derecesini derecesini belirlemeyi amaçlamaktadır (Cohen, Manion \& Morrison, 2000).

\section{Evren ve Örneklem}

Araştırmanın evrenini 2018-2019 eğitim- öğretim yılında Necmettin Erbakan Üniversitesi, 
Ahmet Keleşoğlu Eğitim Fakültesinde öğrenim gören öğretmen adayları oluşturmaktadır. Evren büyüklügü nedeniyle basit rastsal örnekleme yöntemi ile örneklem alınmış, rasgele seçilmiş 345 öğretmen adayı örnekleme dahil edilmiștir. Örnekleme ait demografik bilgiler Tablo 1'de verilmiştir.

Tablo 1. Katılımcllara ait demografik bilgiler

\begin{tabular}{cccc}
\hline Değişken Adı & Değerler & n & \% \\
\hline \multirow{2}{*}{ Cinsiyet } & Erkek & 93 & 27,0 \\
& Kadın & 252 & 73,0 \\
\hline \multirow{2}{*}{ Sınıf } & 1 & 169 & 49,0 \\
& 2 & 95 & 27,5 \\
& 3 & 31 & 9,0 \\
Mezun olunan Lise Türü & 4 & 50 & 14,5 \\
\hline \multirow{2}{*}{ Aile Aylık Ortalama Gelir } & Meslek Lisesi & 55 & 15,9 \\
& Öğretmen Lisesi & 28 & 8,1 \\
& Anadolu Lisesi & 189 & 54,8 \\
& Diğer & 73 & 21,1 \\
\hline Toplam & $2000^{\prime}$ den az & 100 & 29,0 \\
& 2001- 5000 arası & 205 & 59,4 \\
& $5000^{\prime}$ den fazla & 40 & 11,6 \\
\hline
\end{tabular}

Tablo 1 incelendiği zaman katılımcıların \% 73'ünün kadın; \% 49,0'unun 1 . Sınıf ve aile aylık ortalama gelirlerinin \% 59,4'ünün 2001- 5000 arası olduğu görülmektedir.

\section{Veri Toplama Araçları}

Öğretmen adaylarının özgüven düzeylerini belirlemek için Akın (2007) tarafından geliştirilen "Özgüven Ölçeği" ile öğretmen adaylarının teknoloji tutumlarını belirlemek için Şad ve Nalçacı (Şad ve Nalçacı,2015) tarafından geliştirilen "Öğretmen Adayları için Bilgi ve İletişim Teknolojileri (BIT) Yeterlilik Algısı Ölçeği” kullanılmıştır.

\section{Özgüven Ölçeği}

Öğretmen adaylarının özgüven ile ilgili verilerini toplayabilmek amacı ile Akın (2007) tarafından geliştirilen "Özgüven Ölçeği" kullanılmıştır. Ölçek 33 madde ve iki alt boyuttan ve kendini değerlendirmeye yönelik 5'li Likert tipi ifadelerden oluşmaktadır. Özgüven ölçeğinin puanlanmasında toplam puan ve alt ölçek puanları elde edilmektedir. İç özgüven alt boyutu 17 maddeden ve bireyin kendini sevmesi, tanıması, açık hedefler belirlemesi, bilmesi gibi özellikleri değerlendirmektedir. Dış özgüven alt boyutu ise 16 maddeden ve bireylerin dış çevre ve sosyal yaşamalarına yönelik özgüvenleriyle ilişkili olup, kolay iletişim kurabilme, kendini sağlıklı biçimde ifade edebilme, duygularını kontrol edebilme ve risk alabilme gibi özelliklerini kapsamaktdır (Akın, 2007). Ölçeğin iç tutarlılık güvenirlik katsayıları ölçeğin bütünü için 0.91 iç özgüven faktörü için 0.89 ve diş özgüven faktörü için 0.76 olarak bulunmuştur.

\section{Öğretmen Adayları için Bilgi ve İletişim Teknolojileri (BİT) Yeterlilik Algısı Ölçeği}

Öğretmen adaylarının teknoloji tutumlarıyla ilgili verilerini toplayabilmek amacı ile Şad ve Nalçacı (2015) tarafından geliştirilen "Öğretmen Adayları için Bilgi ve İletişim Teknolojileri (BİT) Yeterlilik Algısı Ölçeği” kullanılmıştır. Beşli likert şeklinde ifadelerden oluşan toplam 30 maddeden ve tek faktörden oluşan ölçeğin yapı geçerliği için açıklayıcı faktör analizi işlemi sonucunda faktörün toplam varyansın \%48.03'ünü açıklayabildiği ifade edilmiştir. Ölçek maddelerin iç tutarlılık açısından güvenirliği Cronbach Alpha ve Guttman Test-Yarılama formülleri kullanılarak hesaplanmıștır. Cronbach Alpha katsayısı 0.96 ve Guttman iki yarı 
tutarlılık katsayısı 0.93 olarak hesaplanmıştır.

\section{Verilerin Analizi}

Veri toplama araçlarından elde edilen veriler öncelikli olarak bilgisayar ortamına aktarılmıştır. Geçerli olan verilere ait beşli likert maddelerin bilgisayar ortamına aktarılmasında 1- Hiç katılmıyorum, 5- Kesinlikle katılıyorum şeklinde bir puanlama yapılmıştır. Verilerin analizinde öncelikli olarak betimsel istatistiklerden yüzde ve frekans kullanılmıştır. Öğretmen adaylarının cinsiyetlerine göre teknoloji kullanım yeterlikleri ve özgüven düzeyleri arasındaki farklılı̆̆ belirlemek için bağımsız örneklem $t$ testi, aylık ortalama gelir düzeyine göre farklılıkları belirlemek içinse Tek Yönlü Varyans Analizi (ANOVA) uygulanmıştır. Teknoloji kullanım yeterlik algı düzeyi ile özgüven düzeyi arasındaki ilişkiyi belirlemek içinse Pearson Momentler Çarpım Katsayısı kullanılmıştır. Verilerin analizlerinde Statistical Package for the Social Sciences (SPSS) 22.0 programından yararlanılmıș, anlamlılık düzeyi olarak .05 alınmıștır.

Her iki ölçek maddeleri ile ölçek geneline ait verilerin yorumlanmasında aritmetik ortalama puanlarından yararlanılmış, düşük, orta ve yüksek düzey olarak üç değerlendirme kriteri belirlenmiştir. (Maksimum puan-Minimum puan) / Değerlendirme Aralığı formülünce en yüksek puan 5, en düşük puan 1 ve değerlendirme aralığı (düşük, orta ve yüksek) 3 olmak üzere (5-1) / 3 formülü kapsamında öğretmen adaylarının değerlendirilmesine yönelik kriter ve aralık değerleri Tablo 2'deki şekilde kabul edilmiştir.

Tablo 2. Özgüven ve Teknoloji Yeterlik Algısı Değerlendirme ölçütleri

\begin{tabular}{cc}
\hline Değerlendirme Aralığı & Değerlendirme Kriteri \\
\hline $1.00-2.33$ & Düşük Düzey \\
$2.34-3.66$ & Orta Düzey \\
$3.67-5.00$ & Yüksek Düzey \\
\hline
\end{tabular}

\section{BULGULAR}

Araştırma kapsamında öğretmen adaylarının BİT kullanım ve özgüvenleri yeterlik algılarına yönelik elde edilen bulgular verilmiştir.

\section{Öğretmen Adaylarının BíT Kullanım Yeterlik Algıları}

Araştırma alt amaçları doğrultusunda öncelikli olarak öğretmen adaylarının BíT kullanım yeterlik algıları incelenmiş elde edilen analiz sonuçları Tablo 3'te verilmiştir.

Tablo 3. Öğretmen Adaylarının BİT Kullanım Yeterlik Algıları

\begin{tabular}{c|l|c|c}
\hline $\begin{array}{c}\text { Sira } \\
\text { No }\end{array}$ & \multicolumn{1}{|c|}{ Madde } & $\overline{\mathbf{X}}$ & \multicolumn{1}{|c}{ Ss } \\
\hline 1 & Ders materyallerimi hazırlarken internetten yararlanabilme, & 4,13 &, 896 \\
\hline 2 & $\begin{array}{l}\text { Öğretmen olarak kendimi geliştirmek amacıyla bilgi ve iletişim teknolojilerinden } \\
\text { yararlanabilme, }\end{array}$ & 3,97 &, 905 \\
\hline 3 & $\begin{array}{l}\text { Öğretmen olarak verimliliğimi artırmak amacıyla bilgi ve iletişim teknolojilerinden } \\
\text { yararlanabilme. }\end{array}$ & 3,96 &, 909 \\
\hline 4 & Ders notu, sunum, çalışma kâğıdı vb. materyalleri bilgisayarda hazırlayabilme, & 3,94 &, 935 \\
\hline 5 & Ders materyallerimi akıllı tahta, projektör, tepegöz vb. gibi araçlarla sunabilme, & 3,94 &, 990 \\
\hline 6 & $\begin{array}{l}\text { Ders materyallerimi hazırlarken Word, Excel, Powerpoint vb. yazılımlardan } \\
\text { faydalanabilme, }\end{array}$ & 3,92 &, 977 \\
\hline 7 & $\begin{array}{l}\text { Ölçme ve değerlendirme sonuçlarının okul yönetimi, veli ve diğer eğitimcilerle paylaşmak } \\
\text { için bilgi ve iletişim teknolojilerini kullanabilme, }\end{array}$ & 3,90 &, 947 \\
\hline 8 & İnternette dersimin öğretimiyle ilgili veri tabanları ve kaynaklara ulaşabilme, & 3,89 &, 934 \\
\hline 9 & Ders planında, derste kullanacağım bilgi ve iletişim teknolojilerine yer verebilme & 3,88 &, 896 \\
\hline 10 & $\begin{array}{l}\text { Sinıfımdaki bilgi ve iletiş̧im teknolojilerini güvenli bir şekilde kullanabilmek için gerekli } \\
\text { önlemleri alabilme }\end{array}$ & 3,87 &, 914 \\
\hline 11 & $\begin{array}{l}\text { Öğrencilerin sınav sonuçlarını analiz ederken bilgi ve iletişim teknolojilerini } \\
\text { kullanabilme, }\end{array}$ & 3,87 &, 881 \\
\hline
\end{tabular}




\begin{tabular}{|c|c|c|c|}
\hline 12 & $\begin{array}{l}\text { Öğrencilerin ölçme sonuçlarını tablo, grafik vb. görsellere dönüştürmede bilgi ve iletişim } \\
\text { teknolojilerini kullanabilme }\end{array}$ & 3,86 & ,946 \\
\hline 13 & $\begin{array}{l}\text { Bilgi ve iletişim teknolojilerinin kullanım ilkelerini dikkate alarak öğrenme ortamını } \\
\text { düzenleyebilme, }\end{array}$ & 3,85 & ,951 \\
\hline 14 & $\begin{array}{l}\text { Bilgi ve iletişim teknolojilerini öğrencilerin sağlığına ve güvenliğine dikkat ederek } \\
\text { kullanmak için gerekli önlemleri alabilme, }\end{array}$ & 3,85 & ,932 \\
\hline 15 & Öğrenci merkezli öğretim stratejilerini destekleyen teknolojileri kullanabilme, & 3,83 & ,896 \\
\hline 16 & $\begin{array}{l}\text { Bilgi ve iletişim teknolojilerini farklı öğrencilerin ihtiyaçlarını karşılayacak şekilde } \\
\text { kullanabilme, }\end{array}$ & 3,82 & ,868 \\
\hline 17 & $\begin{array}{l}\text { Branşımın öğretimiyle ilgili internetteki kaynakları doğruluk ve uygunlukları açısından } \\
\text { değerlendirebilme }\end{array}$ & 3,81 & ,927 \\
\hline 18 & Branşımın öğretimiyle ilgili bilgi ve iletişim teknolojilerindeki gelișmeleri izleyebilme, & 3,80 & 1,862 \\
\hline 19 & $\begin{array}{l}\text { Öğrenme ortamını düzenlerken bilgisayar, projektör, tepegöz, akıllı tahta gibi } \\
\text { teknolojilerin kullanım ilkelerini dikkate alabilme }\end{array}$ & 3,79 & ,971 \\
\hline 20 & $\begin{array}{l}\text { Öğrencilerin ilgi ve ihtiyaçlarına uygun öğrenme ortamlarını hazırlamada bilgi ve iletişim } \\
\text { teknolojilerinden yararlanabilme }\end{array}$ & 3,78 & ,923 \\
\hline 21 & $\begin{array}{l}\text { Bilgi ve iletişim teknolojilerini etkili bir şekilde kullanabilmeyi gelecekte öğrencilerime } \\
\text { öğretebilme, }\end{array}$ & 3,75 & ,897 \\
\hline 22 & Öğretim sürecinde gerekli teknolojileri uygun bir şekilde kullanabilme, & 3,70 & ,890 \\
\hline 23 & $\begin{array}{l}\text { Bilgi ve iletişim teknolojilerini kullanarak sınıfımdaki farklı öğrencilere özel materyal } \\
\text { hazırlayabilme, }\end{array}$ & 3,69 & ,913 \\
\hline 24 & $\begin{array}{l}\text { Alanımın öğretimiyle ilgili geliştirilmiş yazılımları doğruluk ve uygunlukları açısından } \\
\text { değerlendirebilme }\end{array}$ & 3,68 & ,960 \\
\hline 25 & $\begin{array}{l}\text { Bilgi ve iletişim teknolojileri ile ilgili yasal ve ahlâki sorumlulukları öğrencilere } \\
\text { kazandırabilme, }\end{array}$ & 3,64 & ,933 \\
\hline 26 & Teknoloji ile ilgili temel kavram ve uygulamaları bilme, & 3,64 & ,921 \\
\hline 27 & Bilgi ve iletişim teknolojilerinin kullanımına ilişkin yasal ve ahlâki sorumlulukları bilme, & 3,63 &, 908 \\
\hline 28 & $\begin{array}{l}\text { Bilgi ve deneyimlerimi diğer meslektaşlarımla paylașmak amacıyla on-line dergi, paket } \\
\text { yazllımlar, eposta vb. gibi bilgi ve iletişim teknolojilerinden yararlanabilme, }\end{array}$ & 3,58 & ,976 \\
\hline 29 & Öğrencilerime bilgi ve iletişim teknolojilerinin kullanımı konusunda model olabilme, & 3,58 & ,980 \\
\hline 30 & Bilgisayar, projektör, tepegöz, akıllı tahta gibi araçların bakımını yapabilme, & 3,00 & 1,179 \\
\hline \multicolumn{2}{|c|}{ BİT Kullanım Yeterlik Algısı Ortalaması } & 3,78 &, 670 \\
\hline
\end{tabular}

Öğretmen adaylarının BİT yeterlilik algılarının belirlenmesi amacıyla hem ölçekten aldıkları toplam puan, genel aritmetik ortalaması hem de her bir kazamınım ifadesine ilişkin yeterlilik algıları ayrı ayrı incelenmiştir. Öğretmen adaylarının ölçekten aldıkları ortalama puanı $\overline{\mathrm{x}}=3,78^{\prime}$ dir. Bu açıdan öğretmen adaylarının BİT yeterlik algılarının yüksek düzeyde $(\overline{\mathrm{x}}=\geq 3.67)$ olduğu ifade edilebilir. Öğretmen adaylarının her bir maddeye ilişkin yeterlilik algılarının puan ortalamaları ve standart sapmaları en yüksekten en düşüğe doğru sıralanmış olarak Tablo 3'te verilmiştir.

Tablo 3 incelendiğinde, öğretmen adaylarının yeterlik algılarının "30. Bilgisayar, projektör, tepegöz, akıllı tahta gibi araçların bakımını yapabilme" $(\bar{x}==3,00)$ kazanım için orta düzeyde kaldığı, diğer kazanımlar için ise yüksek düzeyde olduğu görülmektedir.

\section{Öğretmen Adaylarının Özgüven Düzeyleri}

Araştırma kapsamında araştırılan bir diğer konu ise öğretmen adaylarının özgüven düzeyleri olmuştur. Bu doğrultuda araștırmaya katılan 345 öğretmen adayının özgüven düzeyleri analiz edilmiş, sonuçlar Tablo 4'te verilmiştir. 
Tablo 4. Öğretmen Adaylarının Özgüven Düzeyleri (n=345)

\begin{tabular}{|c|c|c|c|}
\hline $\begin{array}{c}\text { Sira } \\
\text { No }\end{array}$ & Madde ve Faktörler & $\overline{\mathbf{X}}$ & SS \\
\hline 1 & Verdiğim kararların arkasında dururum & 4,29 & 2,340 \\
\hline 2 & İstediğim șeyleri elde etmek için mücadele edebilirim. & 4,22 & ,773 \\
\hline 3 & Kendimi severim. & 4,10 & ,885 \\
\hline 4 & Öz-eleştiri yapabilirim & 4,08 & 851 \\
\hline 5 & Problemlerimin üstesinden gelebileceğime inanırım. & 4,04 &, 730 \\
\hline 6 & Kendi kendime yetebileceğime inanırım. & 4,03 & 2,836 \\
\hline 7 & Kendimi ve bașkalarını olduğu gibi kabul ederim. & 4,02 & 874 \\
\hline 8 & Değerli birisi olduğuma inanırım. & 3,97 & ,894 \\
\hline 9 & Kendimle barıșık bir insanım. & 3,96 & ,941 \\
\hline 10 & Yaşamdaki zorluklarla baș edebilirim & 3,87 & 791 \\
\hline 11 & Başarısız olduğumda hemen pes etmem. & 3,85 & ,860 \\
\hline 12 & Seçimlerimde başkalarına bağımlı değilimdir. & 3,83 & ,911 \\
\hline 13 & Sorumluluk almaktan çekinmem & 3,77 & ,875 \\
\hline 14 & Kendimi bașarılı bir insan olarak görürüm & 3,75 & ,781 \\
\hline 15 & Sıkıntılı anlarımda bile olumlu düșünmeye çalıșırım. & 3,35 & 1,080 \\
\hline 16 & Benim için aşılamayacak sorun yoktur. & 3,29 & ,973 \\
\hline 17 & Kolay karar verebilirim. & 3,14 & 1,153 \\
\hline \multicolumn{2}{|c|}{ İç Özgüven Düzey Ortalaması } & 3,85 &, 554 \\
\hline 18 & Başkalarının görüşlerine saygı gösteririm. & 4,37 & ,690 \\
\hline 19 & Gerektiğinde sonuna kadar hakkımı savunurum. & 4,30 & 2,727 \\
\hline 20 & Anlamadığım konularda bașkalarına soru sorabilirim & 4,15 & ,817 \\
\hline 21 & Yeni girdiğim ortamlara uyum sağlarım. & 3,89 & ,929 \\
\hline 22 & Kendimi rahat bir şekilde ifade edebilirim. & 3,85 & ,857 \\
\hline 23 & Bașka insanlarla kolaylıkla iletișim kurabilirim & 3,85 & ,897 \\
\hline 24 & Diğer insanların eleștirilerini anlayıșla karșılayabilirim. & 3,83 & ,854 \\
\hline 25 & Düșüncelerimi ifade ederken başkalarından çekinmem. & 3,82 & ,955 \\
\hline 26 & Başka insanların övgülerini hak ettiğime inanırım & 3,82 & ,965 \\
\hline 27 & Kolay arkadaş edinebilirim & 3,77 & 1,009 \\
\hline 28 & Çevremde yeteri kadar güvenebileceğim insan vardır. & 3,70 & 1,018 \\
\hline 29 & Sosyal etkinliklere katılmaktan çekinmem. & 3,64 & ,995 \\
\hline 30 & Sosyal bir insan olduğuma inanırım. & 3,51 & 1,049 \\
\hline 31 & Ön plana çımaktan korkmam. & 3,50 & 1,000 \\
\hline 32 & Aktif birisi olduğumu düşünürüm. & 3,49 & ,997 \\
\hline 33 & Başkalarının yanında heyecanımı kontrol edebilirim. & 3,42 & ,943 \\
\hline \multicolumn{2}{|r|}{ Dış Özgüven Düzey Ortalaması } & 3,80 &, 588 \\
\hline \multicolumn{2}{|c|}{ ÖZGÜVEN DÜZEYİ GENELİ } & 3,83 &, 525 \\
\hline
\end{tabular}

Tablo 4 incelendiğinde öğretmen adaylarının özgüven düzeylerinin $(\bar{x}=3,83)$ yüksek düzeyde olduğu görülmektedir. Yine Tablo 4'ten görüleceği üzere öğretmen adaylarının hem iç özgüven düzeylerinin $(\bar{x}=3,85)$ hem de diş özgüven düzeylerinin $(\bar{x}=3,80)$ yüksek olduğu görülebilir.

Öğretmen adaylarının iç özgüven düzeylerine yönelik bazı maddeler incelendiğinde "1. Verdiğim kararların arkasında dururum" ( $\bar{x}=4,29)$; "2. İstediğim şeyleri elde etmek için mücadele edebilirim." $(\overline{\mathrm{x}}=4,22)$; ve"3. Kendimi severim." $(\overline{\mathrm{x}}=4,10)$ maddelerinin özgüven düzeylerinin yüksek düzeyde iken "17. Kolay karar verebilirim." ( $\bar{x}=3,14)$; "16. Benim için aşllamayacak sorun yoktur." ( $\overline{\mathrm{x}}=3,29)$; ve"15. Sıkıntılı anlarımda bile olumlu düşünmeye çalışırım." $(\overline{\mathrm{x}}=3,35)$ maddelerinin orta düzeyde olduğu görülmektedir. Benzer şekilde dış özgüven düzeylerine yönelik bazı maddeler incelendiğinde "18. Başkalarının görüşlerine saygı gösteririm." $(\overline{\mathrm{x}}=4,37)$; "19. Gerektiğinde sonuna kadar hakkımı savunurum." ( $\bar{x}=4,30)$; ve"20. Anlamadığım konularda başkalarına soru sorabilirim." ( $\bar{x}=4,15)$ maddelerinin özgüven düzeylerinin yüksek düzeyde iken "33. Başkalarının yanında heyecanımı kontrol edebilirim." ( $\overline{\mathrm{x}}=3,42)$; "32. Aktif birisi olduğumu düşünürüm." ( $\bar{x}=3,49)$; ve"31. Ön plana çlkmaktan korkmam." $(\bar{x}=3,50)$ maddelerinin orta düzeyde olduğu görülmektedir. 


\section{Algiları \\ Öğretmen Adaylarının Cinsiyete Göre Özgüven Düzeyleri ile BíT Kullanım Yeterlik}

Öğretmen adaylarının özgüven düzeyleri ile BİT kullanım yeterlik algılarının cinsiyetlerine göre farklılaşıp farklılaşmadığını belirlemek yapılan analiz sonuçları Tablo 5 'te verilmiştir.

Tablo 5. Öğretmen Adaylarının Özgüven ve BİT Yeterlik Algılarının Cinsiyetlerine Göre TTesti Sonuçları

\begin{tabular}{|c|c|c|c|c|c|c|c|}
\hline & Cinsiyet & $\mathbf{N}$ & $\bar{X}$ & Ss & Sd & $\mathbf{t}$ & $\mathbf{p}$ \\
\hline Özgüven Düzeyi & $\begin{array}{l}\text { Erkek } \\
\text { Kadın }\end{array}$ & $\begin{array}{r}93 \\
252 \\
\end{array}$ & $\begin{array}{l}3,92 \\
3,80 \\
\end{array}$ & $\begin{array}{l}0,501 \\
0,531 \\
\end{array}$ & 343 & 1.846 & .066 \\
\hline BİT Kullanım Yeterlik Algısı & $\begin{array}{l}\text { Erkek } \\
\text { Kadın }\end{array}$ & $\begin{array}{r}93 \\
252 \\
\end{array}$ & $\begin{array}{l}3,86 \\
3,75 \\
\end{array}$ & $\begin{array}{l}0,724 \\
0,648 \\
\end{array}$ & 343 & 1.275 & .203 \\
\hline
\end{tabular}

$* \mathrm{p}<.05$

Tablo 5 incelendiğinde öğretmen adaylarının özgüven düzeylerinin cinsiyete göre farklılaşmadığı görülebilir ( $\mathrm{t}=1.846 ; \mathrm{p}>.05)$. Bu açıdan gerek kadın $(\overline{\mathrm{x}}=3.80)$ gerek erkek $(\overline{\mathrm{x}}=3.92)$ öğretmen adaylarının eşit ve ileri düzeyde özgüvene sahip oldukları görülmektedir. Diğer yandan bir diğer değişken olan BİT yeterlik algılarının cinsiyete göre farklılı̆̆ına yönelik analiz işlemi sonucunda farklılık bulunmadığı da Tablo 5 'ten görülmektedir ( $\mathrm{t}=1.275 ; \mathrm{p}>.05)$. Erkek öğretmen adaylarının BíT kullanım yeterlik algıları ( $\overline{\bar{x}}=3.86)$ ile kadınların BíT kullanım yeterlik algıları $(\overline{\mathrm{x}}=3.75)$ arasındaki fark istatistiki açıdan anlamlı değildir.

\section{Aylık Gelir Ortalamalarına Göre Öğretmen Adaylarının Özgüven Düzeyleri ile BíT Kullanım Yeterlik Algıları}

Öğretmen adaylarının aylık gelir düzeylerinin onların BíT kulalnım yeterlik algıları ile özgüven düzeyleri üzerinde farklılığa neden olup olmadığını belirlemek için, ilgili değișkenler arasından tek yönlü varyans analizi işlemi gerçekleștirilmiş, sonuçlar Tablo 6'te verilmiştir.

Tablo 6. Öğretmen Adaylarının Aylık Ortalama Gelir Düzeylerine Göre Özgüven Düzeyleri ile BİT Kullanım Yeterlik Algılarının Karşılaştırılması

\begin{tabular}{|c|c|c|c|c|c|c|c|c|c|c|c|}
\hline & Aylık ort. Gelir & $\mathbf{n}$ & $\overline{\boldsymbol{X}}$ & sS & $\begin{array}{c}\text { Varyansın } \\
\text { Kaynağı }\end{array}$ & $\begin{array}{l}\text { Kareler } \\
\text { Toplamı }\end{array}$ & Sd & $\begin{array}{c}\text { Kareler } \\
\text { Ort. }\end{array}$ & $\mathbf{F}$ & $\mathbf{p}$ & $\begin{array}{c}\text { Anlamlı } \\
\text { Fark }\end{array}$ \\
\hline \multirow{3}{*}{ 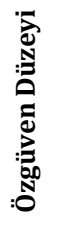 } & A- 2000 tlden az & 100 & 3,70 &, 524 & Gruplararası & 3,298 & 2 & 1,649 & 6,15 &, $002 *$ & $\mathrm{~A}-\mathrm{C}$ \\
\hline & B- 2001-5000 tl & 205 & 3,85 &, 524 & Gruplariçi & 91,593 & 342 & ,268 & & & \\
\hline & C- 5000 tlden fazla & 40 & 4,03 & ,460 & Toplam & 94,891 & 344 & & & & \\
\hline \multirow{3}{*}{ 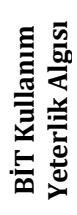 } & A- 2000 tlden az & 100 & 3,65 & ,657 & Gruplararası & 2,430 & 2 & 1,215 & 2,73 &, 067 & - \\
\hline & B- 2001-5000 tl & 205 & 3,83 & ,656 & Gruplariçi & 152,102 & 342 & ,445 & & & \\
\hline & C- 5000 tlden fazla & 40 & 3,83 & ,740 & Toplam & 154,532 & 344 & & & & \\
\hline
\end{tabular}

$* \mathrm{p}<.05$

Tablo 6 incelendiğinde öğretmen adaylarının aylık ortalama gelir düzeyinin onların özgüven düzeyleri üzerinde farklılığa neden oldukları görülebilir $\left(\mathrm{F}_{(2-342)=6.157 ;} \mathrm{p}<.05\right)$. Farklılığın hangi gruplar arasında olduğunu belirlemek için yapılan scheffe testi sonucuna göre aylık gelir düzeyi 5000 tl'den fazla olanların özgüven düzeylerinin $(\overline{\mathrm{x}}=4.03) 2000 \mathrm{tl}$ 'den az olanların özgüven düzeyinden ( $\bar{x}=3.70)$ istatistiki olarak anlamlı düzeyde farklılaştığı ifade edilebilir. 
Diğer yandan BİT kullanım yeterlik algıları açısından öğretmen adaylarının aylık ortalama gelir düzeylerinin önemli bir farklılığa neden olmadıkları görülmektedir $\left(\mathrm{F}_{(2-342)}=2.731 ; \mathrm{p}>.05\right)$. Diğer bir ifade ile BİT kullanım yeterlik algıları açısından aylık ortalama gelirleri 2000 tl'den az $(\overline{\mathrm{x}}=3.65), 2000-5000$ tl arası ( $\overline{\mathrm{x}}=3.83)$ ve 5000 tl'den fazla $(\overline{\mathrm{x}}=3.83)$ arasındaki farklılık istatistiki olarak anlamlı değildir.

\section{Öğretmen Adaylarının Özgüven Düzeyleri ile BİT Kullanım Yeterlik Algıları Arasındaki İliş̧ki}

Araştırma kapsamında öğretmen adaylarının BİT kullanım yeterlik algıları ile özgüven düzeyleri arasındaki ilişki pearson momentler çarpım katsayısı ile analiz edilmiş, elde edilen bulgular Tablo 7'da verilmiştir.

Tablo 7. Öğretmen adaylarının Özgüven Düzeyleri ile BİT Kullanım Yeterlik Algıları Arasındaki Korelasyon Düzeyi (n=345)

\begin{tabular}{lcccc}
\hline & İç Özgüven & Dış Özgüven & Özgüven Genel & $\begin{array}{c}\text { BíT Kullanım } \\
\text { Yeterlik Algısı }\end{array}$ \\
\hline İç Özgüven & 1.00 &, $694^{* *}$ &, $920^{* *}$ &, $\mathbf{4 4 1 ^ { * * }}$ \\
Dış Özgüven & & 1.00 &, $920^{* *}$ &, $\mathbf{4 0 9 ^ { * * }}$ \\
Özgüven Genel & & 1.00 &, $\mathbf{4 6 2 ^ { * * }}$ \\
\hline
\end{tabular}

** $\mathrm{p}<.01$

Tablo 7 incelendiğinde, öğretmen adaylarının Bi̇T kullanım yeterlik algıları ile özgüven düzeyleri arasında orta düzey ve pozitif yönlü bir ilișkinin var olduğu görülebilir $(\mathrm{r}=.462 ; \mathrm{p}<.01)$. Benzer şekilde BİT kullanım yeterlik algısı ile hem iç özgüven düzeyi $(r=.441 ; \mathrm{p}<.01)$ ile hem de dış özgüven düzeyi ( $\mathrm{r}=.409 ; \mathrm{p}<.01)$ arasında orta düzeyli ve pozitif yönlü bir ilişki söz konusudur. $\mathrm{Bu}$ açıdan öğretmen adaylarının BİT kullanım yeterlik algılarının özgüven düzeyleri arasında ilişkinin var olduğu önemli bir sonuç olarak ifade edilebilir.

\section{SONUÇ ve TARTIŞMA}

$\mathrm{Bu}$ araștırmada öğretmen adaylarının özgüven düzeyleri, BİT kullanım yeterlik algılarının cinsiyet, aylık ortalama gelir değişkenlerine göre değişip değişmediği incelenmiştir. Ayrıca öğretmen adaylarının özgüvenleri ile BİT kullanım yeterlikleri arasındaki ilişki araştırılmıştır.

Araştırma sonuçları incelendiğinde öğretmen adaylarının özgüven düzeyleri ile BİT kullanım yeterlilik algılarının cinsiyete göre istatistik açıdan anlamlı bir fark bulunmamıştır. Düz, Öztürk Karataş (2017), tarafından yapılan Beden Eğitimi ve Spor Yüksekokulu öğrencilerinin liderlik yönelimleri ve özgüven davranışlarının incelenmesi araştırması incelendiğinde de cinsiyete göre özgüvende istatistiksel olarak bir farklılık gözlenmemiștir. Timur, Yılmaz ve Timur (2013), öğretmen adaylarının bilgisayar kullanımına ilişkin öz yeterlilik algılarını inceledikleri araştırmada öğretmen adaylarının bilgisayar kullanımına ilişkin öz yeterlilik algılarında da cinsiyete göre herhangi bir farklılık olmadığını ifade etmiştir.

Öğretmen adayların aylık ortalama gelirlerine göre özgüven düzeyleri ve BİT yerlilik algıları arasındaki ilişki incelendiğinde ise öğretmen adaylarının aylık ortalama gelir düzeylerine göre onların özgüven düzeylerinin farklılaştığı, ancak BIT kullanım yeterliğinin farklılaşmadığı görülmüştür. Aylık ortalama geliri yüksek olanlar, düşük olanlara oranla daha özgüvenli olduklarını ifade etmişlerdir. Bandura öz-yeterlik kavramını, davranışların oluşmasında etkili olan bir nitelik ve "bireyin, belli bir performansı göstermek için gerekli etkinlikleri organize edip, başarılı olarak yapma kapasitesi hakkında kendine ilişkin yargısı" olarak tanımlamaktadır (Bandura, 1997, s. 3). Bu açıdan maddi gelirin burada ifade edilen başarılı olma yönünde sağlanılan/elde edilen imkanları artırması bu nedenle özgüvenin de yüksek olduğu çıkarımı 
yapılabilir.

Nihai amaç olarak öğretmen adaylarının özgüven düzeyleri ile BİT kullanım yeterlilik algıları arasında orta düzeyli ve pozitif yönlü bir ilişki bulunmuştur. Bir başka ifade ile özgüveni yüksek olan öğretmen adaylarının teknoloji kullanım yeterlikleri de artmaktadır. Araștırmada araştırılan değişken olarak özgüvenin teknoloji kullanımına yönelik özgüvenden farklılaştığı vurgulanmalıdır. Göktaş (2011) yaptığı araştırmasında öğretmen adaylarının BİT’lere yönelik özgüven algılarını cinsiyet, bölüm türü gibi değişkenlere göre araștırmıștır. Ancak bu araștırmada psikolojik bir değişken ve kişilik özelliği olarak bireylerin sahip oldukları özgüven düzeylerinin teknoloji kullanımı üzerindeki etkisi araştırılmış ve pozitif yönlü-orta dereceli bir ilişki bulunmuştur. Soner (1995), özgüveni yüksek kişilerin değiştiremeyeceği koşulları huzur içinde kabul eden, değiștirebileceği koşulları değiștirecek cesareti gösteren ve değiştirebileceği koşullarla değiştiremeyeceklerini ayırt edebilecek bilgeliğe sahip bir insan olarak nitelendirmektedir. Bu açıdan teknoloji kullanımının sağladığı yeniliklerin ve kolaylıkların özgüven üzerinde önemli katkı sağladığı, farkın bu nedenle ortaya çıtığı ifade edilebilir.

\section{ÖNERILLER}

Araştırma sonucunda öğretmen adaylarının özgüvenleri ile BỉT yeterlilik algıları arasında orta düzey ve pozitif yönlü bir ilişki tespit edilmiştir. İlişki doğrultusunda öğretmen adaylarına teknoloji kullanımının öğretiminde psikolojik boyutlarında dikkate alınması önerilebilir. Bu yönü ile teknoloji kullanımı odaklı eğitimin bireyselleştirilmesi için farklı psikolojik değişkenlerin ele alındığı yeni araştırmaların yapılması da önerilebilir.

\section{KAYNAKÇA}

Akın, A. (2007). Öz-güven Ölçeği'nin geliştirilmesi ve psikometrik özellikleri. Abant İzzet Baysal Üniversitesi Eğitim Fakültesi Dergisi, 7(2), 167-176.

Aksoy, H.H. (2003). Uluslararası Karşılaştırma Ölçütlerinin Kullanımı ve Türkiye. Eğitim Bilim Toplum. $1(1), 51-60$.

Altunçekiç, A., Yaman s. ve Koray, Ö. (2005). Öğretmen Adaylarının Öz-yeterlik İnanç Düzeyleri ve Problem Çözme Becerileri Üzerine Bir Araştırma (Kastamonu İli Örneği), Kastamonu Eğitim Fakültesi Dergisi, 13(1), 93-102.

Bandura, A. (1997). Self-efficacy: The exercise of control. New York: Freeman.

Bingöl, O. (2014). Toplumsal Cinsiyet Olgusu ve Türkiye'de Kadınlık. KMÜ Sosyal ve Ekonomik Arastırmalar Dergisi, 16 (1), 108-114.

Cohen, L., Manion, L. \& Morrison, K. (2000). Research methods in education. $5^{\text {th }}$ ed. London New York: Routledge Falmer.

Erdemir, N., Bakırcı, H. ve Eyduran E. (2009). Öğretmen Adaylarının Eğitimde Teknolojiyi Kullanabilme Özgüvenlerinin Tespiti. Türk Fen Eğitimi Dergisi, 6(3), 99-108.

Ertürk, S. (1997). Eğitimde program geliştirme. Ankara: Meteksan A.Ş.

Fidan, N. (1977). Eğitimde Yeni Kavramlar ve İlkeler. Ankara: Tek ışılk Matbaası..

Fraenkel, J. R., Wallen, N. E., \& Hyun, H. H. (2012). How to design and evaluate research in education (8 ${ }^{\text {th }}$ edt.). New York: McGram-Hill Companies.

Franken, R.E. (1988). Human motivation (Second Ed.), Pacific Grove: Brooks/Cole Publishing Company.

Göktaş, Z. (2011). Beden Eğitimi Ve Spor Öğrencilerinin Bilgi Ve Iletişim Teknolojilerine Yönelik Özgüven Algılamaları. Niğde Üniversitesi Beden Eğitimi Ve Spor Bilimleri Dergisi, 5(1), 50-57. 
Komis, V., Ergazakia, M, \& Zogzaa, V. (2007). Comparing Computer-Supported Dynamic Modeling And 'Paper \& Pencil' Concept Mapping Technique In Students' Collaborative Activity. Computers \& Education, 49(4), 991-1017.

McCannon, M., Simon, \& Crews, T. B. (2000). Assessing the technology needs of elementary school teachers. Journal of Technology and Teacher Education, 8(2), 111-121.

Şad, S.N. ve Nalçacı, Ö.İ. (2015). Öğretmen Adaylarının Eğitimde Bilgi ve İletişim Teknolojilerini Kullanmaya İlişkin Yeterlilik Algıları. Mersin Üniversitesi Eğitim Fakültesi Dergisi, 11(1), 177- 197.

Sayan, H. (2016). Okul öncesi eğitimde teknoloji kullanımı. 21.Yüzyılda Eğitim ve Toplum Dergisi, 5(13), 6783.

Shrauger, J. S. (1972). Self-Esteem And Reactions to Being Observed By Others. Journal of Personality and Social Psychology, 23(2), 192-200.

Simon, Y. R. (1983). Pursuit of happiness and lust for powerin technological society. In C.Mitcham \& R. Mackey (Eds.), Philosophy and technology, New York: Free Press.

Soner, O. (1995). Aile Uyumu, Öğrenci Özgüveni Ve Akademik Başari Arasindaki Ilişkiler. Marmara Üniversitesi Atatürk Eğitim Fakültesi Eğitim Bilimleri Dergisi, 12(12), 249-260.

Timur, B., Yılmaz, Ş. ve Timur, S. (2013). Öğretmen Adaylarının Bilgisayar Kullanımına Yönelik Özyeterlik İnançları. Mersin Üniversitesi Eğitim Fakültesi Dergisi, 9(1), 165-174.

Tokinan, B. Ö. (2008). Yaratıcı Dans Etkinliklerinin Motivasyon, Özgüven, Öz-yeterlik ve Dans Performansı Üzerindeki Etkileri. Yayımlanmamış Yüksek Lisans Tezi, Dokuz Eylül Üniversitesi, Eğitim Bilimleri Enstitüsü, İzmir.

Usta, E. ve Korkmaz, Ö. (2010). Öğretmen Adaylarinin Bilgisayar Yeterlikleri Ve Teknoloji Kullanimina Ilişkin Algılari ile Öğretmenlik Mesleğine Yönelik Tutumlari. Uluslararası İnsan Bilimleri Dergisi, 7(1). 


\section{EXTENDED SUMMARY}

\section{INTRODUCTION}

Technology is the application of scientific principles and innovations to solve problems. Technology in its broadest sense is a science application (Aksoy, 2003). All technological devices are seen as the tools that emerge as a result of their application for the solution of scientific problems. In this context, technology is one of the important factors affecting many cultural and social areas in human life. In the light of the information obtained from the literature, it is observed that technology is widely used in education. The use of technology in the field of education, radio, tv, video and overhead projectors, such as the use of tools in schools can go back to the ancient history, but the most important factor in the development and development of today's education system, the use of computers, internet and related tools in the field of education has become widespread (Aksoy, 2003).

Another issue that is dealt with within the scope of the research is self-esteem. Self-confidence, as it is in the literature, is yarg the judgment of the individual to feel valuable" (Bandura, 1997: 11). Selfconfidence is a characteristic of character in general, it is not a type of temporary or permanent behavior (Tokinan, 2008). One's self-confidence status affects the whole life negatively or negatively and it is stated that individuals with high self-confidence have positive results in situations such as academic social and personality character (Shrauger, 1972; Franken, 1988: ss 404). It is known that more positive results are obtained in mental or physiological attitudes of individuals with high self-confidence perception (Altunçekiş, Yaman ve Koray, 2005). Self-esteem was also effective on personality. Individuals with high self-esteem have an innovative personality that loves to conduct research and is aware of their responsibilities (Soner, 1995). Individuals with high self-esteem are individuals who are aware of the opportunities in their hands and conscious about themselves and have characteristic characteristics (Soner, 1995).

The concepts of technology and self-confidence appear to be two concepts that are increasingly important in today's world, leaving a deep impression on people who affect many areas in social cultural terms. The aim of this study is to determine the relationship between these two concepts. In the light of the data obtained in this context, it has been seen that it is important to determine the relationship between teacher candidates' self-confidence levels and technology usage as a psychological factor. Thus, it was aimed to solve the problems of educators who developed technology attitudes and behaviors and could not fulfill their technology attitudes due to self-confidence, and to develop inferences to make better use of technology in education.

The aim of this study is to determine the levels of self-confidence and technology use of teacher candidates and to reveal the relationship between the two variables. For this purpose, answers to the following questions were sought. 1 . What is the level of technology use and self-confidence of teacher candidates? 2. Do pre-service teachers' technology use status and self-confidence levels differ according to gender and average monthly income? 3. What is the relationship between teacher candidates' use of technology and self-confidence levels?

\section{METHOD}

\section{Research Design}

Relational screening model was used in this study, which examined the relationship between teacher candidates' self-confidence and technology use. Relational screening models aim to determine the degree of presence and degree of coexistence between two or more variables (Cohen, Manion \& Morrison, 2000).

\section{Participants}

The population of the study consists of the prospective teachers studying at Ahmet Keleşoğlu Faculty of Education in Necmettin Erabakan University in 2018-2019 academic year. Because of the size of the universe, the sample was taken by simple random sampling method and 345 randomly selected prospective teachers were included in the sample.

\section{Data Collection Tools}

"Self-Confidence Scale tarafindan developed by Akın (2007) to determine teacher candidates 'selfconfidence levels and ve Information and Communication Technologies (ICT) Competence Perception Scale" developed by Şad and Nalçacı (Şad and Nalçacı, 2015) to determine teacher candidates' technology attitudes were used. 


\section{Data Analysis}

The data obtained from the data collection tools were first transferred to the computer environment. Percentage and frequency of descriptive statistics were used primarily in the analysis of the data. Independent sample $t$ test was used to determine the difference between teacher candidates' technology use competencies and self-confidence levels according to gender, and One-Way ANOVA was used to determine differences according to monthly average income level. Pearson Correlation test was used to determine the relationship between technology use adequacy perception level and self-confidence level. Statistical Package for the Social Sciences (SPSS) 22.0 was used in the analysis of the data.

\section{DISCUSSION AND CONCLUSION}

In this study, it has been investigated whether pre-service teachers' self-confidence levels, ICT use proficiency perceptions change according to gender, monthly average income variables. In addition, the relationship between pre-service teachers' self-confidence and ICT use competencies was investigated.

When the results of the study were examined, there was no statistically significant difference between the self-confidence levels of teacher trainees and ICT use adequacy perceptions according to gender. Düz, Öztürk Karataş (2017), conducted by the School of Physical Education and Sports students in the study of the investigation of the leadership orientations and self-confidence behaviors, no statistically significant difference was observed in self-confidence by gender. Timur, Yllmaz and Timur (2013) stated that there was no difference in pre-service teachers' self-efficacy perceptions about computer use according to gender.

When the relationship between self-confidence levels and ICT locality perceptions of teacher candidates according to their monthly average incomes were examined, it was seen that their self-confidence levels differed according to their monthly average income levels, but ICT usage adequacy did not differ. Those with higher monthly average income were more confident than those with low monthly income. Bandura defines self-efficacy as an attribute that is effective in the formation of behaviors and isı selfjudgment about the capacity of an individual to organize and perform the activities necessary to perform a certain performance ((Bandura, 1997, p. 3). In this respect, it can be inferred that self-confidence is also high, as the material income increases the opportunities provided / achieved for success.

Finally, a moderate and positive relationship was found between teacher candidates' self-confidence levels and ICT use competency perceptions. In other words, teacher candidates who have high selfconfidence are increasing their technology use competencies. It should be emphasized that self-confidence as a variable investigated in the research differs from self-esteem towards the use of technology. Göktaș (2011) investigated the pre-service teachers' self-confidence perceptions about ICT by variables such as gender and department type. However, in this study, the effect of self-confidence levels of individuals as a psychological variable and personality trait on the use of technology was investigated and a positive-medium relationship was found. Soner (1995), who accepts the conditions that cannot be changed by high selfconfidence in peace, showing the courage to change the conditions that can change the conditions and change the conditions that can change the wisdom, is a person who can qualify. In this respect, it can be stated that the innovations and conveniences provided by the use of technology make a significant contribution to selfconfidence and the difference arises from this. 